\title{
(2) OPEN ACCESS \\ Speaking truth to power: why leaders cannot hear what they need to hear
}

\author{
Megan Reitz (ㄷ), 'John Higgins ${ }^{2}$
}

${ }^{1}$ Hult International Business School - Ashridge Executive Education Campus,

Berkhamsted, UK

${ }^{2}$ The Right Conversation, London, UK

\section{Correspondence to}

Professor Megan Reitz, Hult International Business School Ashridge Executive Education Campus, Berkhamsted HP4 1NS, UK;

megan.reitz@ashridge.hult.edu

Received 2 October 2020 Revised 13 October 2020 Accepted 15 October 2020

Check for updates

(C) Author(s) (or their employer(s)) 2020. Re-use permitted under CC BY-NC. No commercial re-use. See rights and permissions. Published by BMJ.

To cite: Reitz M, Higgins J. $B M J$ Leader Published Online First: [please include Day

Month Year]. doi:10.1136/

leader-2020-000394

\section{INTRODUCTION}

'Forty years ago, when I was a junior doctor, I decided to speak up about a consultant's malpractice. I went into a senior clinician's office, explained what I had seen and was then told in no uncertain terms 'young man, if you value your future career, you will desist immediately with these claims'. So, I did. And it still haunts me today.'

This story is among thousands we have heard in the National Health Service (NHS). Unfortunately, this kind of situation is not relegated to the past-among stories of real promise and heroic action, the NHS is still grappling with issues of bullying, harassment, exclusion and malpractice. Crucially and similar to the numerous organisations we have examined globally and across every industry sector, leaders are still falling into a critical trap that thwarts their ability to improve the situation.

That is, they are focusing their attention and efforts predominantly on those who feel silenced, urging them to 'be brave', 'speak up' and have the 'courageous conversations' that are required. While this is undoubtedly an important initiative, we need to tackle the cultural context ${ }^{1}$ that means that such bravery and courage is required in the first place.

We need to stop trying to 'fix the silenced' and rather 'fix the system'. This requires us to focus more time and resources on enabling those who are in perceived positions of power to skilfully invite those silenced to speak and then in turn to listen up themselves. It requires us to question and disrupt the very way we socially construct power at work.

In this article, we seek to explore the imperative to speak up and the reasons for silence, the perceptions of speaking and listening up in the NHS, the inevitable blind spots leaders have and what can be done. We draw on our research-a 5-year global, cross-sector, multimethods inquiry into speaking and listening up at work. ${ }^{2}$

In this ongoing research, we hold a particular interest and focus on healthcare-including surveying 1539 UK-based healthcare employees to date, interviewing and engaging hundreds more in workshops, conferences and facilitated cooperative inquiry groups. ${ }^{3}$

As we continue to explore this topic, now focusing specifically on employee activism, our purpose is to make a positive difference to how people speak up and are heard at work.

\section{THE IMPERATIVE TO SPEAK UP: AND THE COST OF SILENCE}

Across all industries, employees' silence costs relationships, creativity, engagement and performance; in keeping with our findings, previous studies have identified that staff frequently know of a problem or opportunity and even how to address it or take advantage, yet stay silent. ${ }^{45}$ In healthcare, silence also costs lives. High-profile cases of malpractice, such as in Mid Staffordshire between 2005 and 2009, or more recently the Gosport hospital deaths and shortcomings in maternity care at Shrewsbury and Telford Hospital NHS Trust, show clearly that when employees fear raising concerns, then things can culminate in tragedy. Forty per cent of our UK healthcare respondents claim they know, or may know something important, that if known about more widely could negatively impact their organisation. Forty-three per cent of these have not spoken up about their concerns formally.

Another imperative to speak up, especially important during this pandemic, relates to sharing the ideas needed for teams to respond with agility to quickly changing circumstances. Nearly three-quarters of respondents claim they have, or may have, ideas or suggestions that could assist their organisation's performance. Over one-third of those, however, have not spoken up with their ideas formally. While the merit of suggestions might differ, it is probable that some valuable ideas remain hidden and the benefit they could bring, lost.

The experience of being heard is not simply a business case though, with some perspectives being 'underpinned by the assumption that (employee voice) is a fundamental democratic right for workers' ${ }^{6}$ It could be argued that creating an environment of psychological safety, ${ }^{7}$ where employees are not in fear of being embarrassed, shamed or punished when they speak up, is also a moral duty. The persistent pursuit of enabling employees to flourish at work, no matter what grade, gender, ethnicity, sexuality, age they are is surely a critical role and definition of an ethical leader.

\section{WHY DO WE STAY SILENT?}

In a word-power, which we see through the Foucauldian framing where it is neither good nor bad, but simply is an ever-present feature of human organising. ${ }^{8}$ More specifically we are drawn to pay attention to 'power imbalance in organisational roles (as) perhaps the most important factor that makes employee silence such a common experience'. Voices are choreographed by the light or shadow that social, personal and institutional power casts, either to illuminate or to hide a particular person, group or agenda item. In organisations we are constantly navigating and constructing perceptions of power difference which in turn affect whether we expect to be heard or ignored and whether we seek others' opinions or not. Power differences translate into fearing the consequences 
of speaking up, especially being socially outcast. The number one reason published in our first report on survey results ${ }^{10}$ for keeping quiet is the fear of being perceived negatively, closely followed by the fear of upsetting or embarrassing another person. At the time of writing this article, with over 5600 global survey respondents, these remain the top two reasons and they are the top two reasons also for UK healthcare respondents.

We are social beings, wanting to belong. To speak up (and to stay silent) is a political act that has consequences for our relationships-not to mention very real consequences for our careers and financial security.

At work, what is accepted as the truth reflects who has power. The powerful shape what goes onto the agenda, whose voices are prioritised and what gets acted on as a result of discussions. ${ }^{11}$ One interviewee reported how one Trust's Board engagement with Workforce Race Equality Standard data focused solely on the Trust's relative standing. The Board knew how to play the league table game, how to explain away or celebrate the Trust's ranking. What it did not seem able to talk about was decades of persistent, systemic discrimination and unfairness. No quick or obvious solution lay to hand, so opening up such conversations were unwelcome.

Too often power itself doesn't get talked about or it is ignored. However, power is a feature of all aspects of human relating and organising, it gets used and abused all the time-and when we pretend it isn't there we fall into investing in often overengineered processes and procedures which simply sustain the status quo, with underlying patterns of power, influence and politics remaining untouched. Barry Oshry's work is particularly strong when it comes to the impact of positional power and how different the world looks depending on whether you are at the top, in the middle or at the bottom. ${ }^{12}$

We stay silent because we fear or respect the power of others. We stay silent when we do not believe we have the power to be heard or to make a difference. We silence others if they do not trust us to be interested in what they have to say. In the early stages of our inquiry we worked with a research diagnostic which indicated that in most cases people were about $30 \%$ more interested in their own opinion than that of others-although in some cases people were reported as being twice or three times more interested in themselves than others.

To be interested in others is more than a technical skill, it involves a specific life philosophy-a fundamental curiosity and humility. A commitment to 'power with or for' rather than 'power over', a framing popularised by Fletcher and one with a strongly gendered layering. ${ }^{13}$

\section{WHO SPEAKS AND WHO LISTENS?}

In our survey, we asked UK healthcare employees how often they felt that junior, middle and senior level employees spoke up in their organisation about issues of malpractice, to challenge ways of working and to offer ideas. Table 1 shows the percentage of respondents who thought that the category of employees would usually, nearly always or always speak up. We also asked the respondents themselves how often they personally would speak

\begin{tabular}{lcccccccccc}
\hline Table 1 & \multicolumn{8}{c}{ How often do people in your organisation speak up } \\
\hline Usually always \% & \multicolumn{1}{c}{ Junior } & \multicolumn{7}{c}{ Middle } & Senior & \multicolumn{1}{c}{ You } \\
\hline About malpractice & 59 & 62 & 66 & 75 & 70 & 84 & 80 & 95 \\
$\begin{array}{l}\text { Challenging ways of } \\
\text { working }\end{array}$ & 21 & 25 & 46 & 54 & 63 & 76 & 48 & 88 \\
Offering ideas & 31 & 36 & 56 & 64 & 64 & 81 & 65 & 91 \\
\hline
\end{tabular}

\begin{tabular}{|c|c|c|c|c|}
\hline \multirow{2}{*}{$\begin{array}{l}\text { Usually always } \% \\
\text { About malpractice }\end{array}$} & \multicolumn{2}{|c|}{ Those senior } & \multicolumn{2}{|c|}{ You } \\
\hline & 68 & 84 & 94 & 98 \\
\hline Challenging ways of working & 35 & 56 & 87 & 95 \\
\hline Offering ideas & 40 & 63 & 91 & 97 \\
\hline
\end{tabular}

up-these results are shown in the last column. Table 2 focuses on listening up, asking respondents whether they listened when others spoke up about malpractice, to challenge ways of working and to offer ideas, and whether they thought those senior to them did. In both tables, the numbers in black represent the responses of junior employees and the numbers in italic blue are the responses of senior employees.

For example, in table 1, 59\% of junior respondents thought that other junior employees would usually, nearly always or always speak up about issues of malpractice. Ninety-one per cent of senior employees claimed they would speak up with ideas. In table 2, 68\% of junior respondents thought that those senior to them would usually always listen up to issues of malpractice. Ninety-seven per cent of senior respondents felt that they would listen up to ideas offered by their colleagues.

When you look at these results in these two tables what is your reaction? Are you surprised? If so, pleasantly or unpleasantly? Do these results mirror your experience? If so, do you regard them as positive, negative or a bit of a mix?

We'd like to draw out three points that we have found to be the case in the overall response to the survey (which includes over 5600 respondents globally and from multiple industries) as well as in the responses from UK healthcare employees:

1. There is a perceived 'hierarchy of speaking up' where those who are junior are less likely to speak up than those who are more senior. Unsurprising perhaps, but this has consequences. It is often the junior employees who, because of the nature of their jobs, see issues and opportunities most immediately, who are most in touch with the actual rather than reported reality. They can be 'secret keepers' and their silence is concerning-particularly if you consider that the perception is that $41 \%$ would not usually speak up about malpractice.

2. The respondents rated their own likelihood of speaking up and listening up more highly in most cases than they rated others. In other words, they felt that they spoke up and listened up-but others did not. This is called the superiority illusion-a bit like when we are asked whether we are good drivers, nearly all of us think we are better than average. We aren't the problem-it's everyone else! The result is that we potentially wait for others to change rather than look in the mirror. We point at others and think they should speak up more or they should listen better rather than examine our own habits. If we all do this, then nothing changes.

3. There is a clear 'optimism' apparent in the responses of senior employees as compared with junior employees. Senior respondents think speaking up and listening up is happening more frequently in every single category, including their self-perceptions.

This last point is so stark and so consequential that we will expand on it below and lead into suggestions for leaders who wish to better enable others to speak up.

\section{THE INEVITABLE 'ADVANTAGE BLINDNESS' OF LEADERS}

We apply labels and titles to one another all the time, in the blink of an eye, according to our blindspots ${ }^{14} 15$ which are not always 


\begin{tabular}{lllll}
\hline Table 3 & What happens when you speak up \\
\hline \% likely & $\begin{array}{l}\text { Speaking up about a } \\
\text { problem }\end{array}$ & Speaking up with an idea \\
\hline Rewarded & 13 & 19 & 22 & 30 \\
Ignored & 48 & 32 & 50 & 28 \\
Suppressed & 33 & 21 & 24 & 13 \\
\hline
\end{tabular}

ones we are aware of or comfortable admitting to (we all live with the history of where and when we grew up, even if we are not condemned to simply recreate it). Job title, gender, ethnicity, age, appearance, accent and a plethora of others. In turn, these labels each convey differing levels of status and authority, depending on how they are socially constructed in a specific context. The same label may convey very different expectations in different organisations, countries or circumstances.

If you are a leader in healthcare, in many cases you will be in possession of several titles and labels that give status and authority. A report last year by the NHS Confederation ${ }^{16}$ states that 'the chairs and non-executive directors on boards that run NHS organisations in England have become less diverse over the last 15 years, with fewer people of black and minority ethnicity and women occupying the positions'. As a leader you may have not only the job title, but also be 'male' and 'white'. These are three labels that are generally socially constructed in ways that convey status. With status comes more positive experiences of speaking up and being heard.

Our research shows that the more senior you are the more you expect positive consequences from speaking up (additionally, if you are male you are also more likely to expect positive outcomes than if you are female).

When asked what would happen if they spoke up about a problem at work, table 3 shows that $13 \%$ of junior UK healthcare respondents thought it likely they would be rewarded, $48 \%$ of them thought they would be ignored and $33 \%$ of them thought they'd be suppressed (in other words prevented from speaking up). Compare this to distinctly more positive responses (although arguably still worryingly poor) from senior respondents. A similar picture emerges when the situation of speaking up with an idea is considered.

If our experience of speaking up is generally positive, we anticipate positive consequences in the future and we are more likely to speak up. Here's the point: we then tend to think that others have similar experiences. We forget or diminish what our colleague Ben Fuchs calls our 'advantage blindness' ${ }^{17}$ —our privileged labels. So, we think it is as easy for everyone to speak up, we put the onus on them and tend to think that we therefore do not need to change our own behaviours.

There is another reason leaders are usually 'optimistic' (or, more provocatively, 'deluded'). Leaders' labels mean that those around them will tend to find them more intimidating. They are then less likely to offer honest feedback (if they are ever asked). This means that unless leaders work very skilfully in their questioning, then they are unlikely to be told, clearly, the true situation, particularly in relation to their own behaviour. This is the irony of attempting to improve one's ability to help others to speak up; others are unlikely to speak up to you to tell you what you need to do.

And if, as you read this, you are thinking 'luckily I'm quite good at that and everyone thinks I'm approachable', while that may be true, it may also be a sign that you have well and truly fallen into the trap we are describing.

So, what can leaders do?

\section{ADVICE TO LEADERS}

Our research points to three areas where leaders can focus in order to become more adept at inviting others to speak up and then listening up. ${ }^{18}$

1. Assume you are scarier than you think. Nearly two-thirds of UK healthcare respondents believe they are never or rarely scary to those junior to them. This is almost certainly an underestimate. Even if leaders hold a clear intent to be approachable and endeavour to make others feel at ease, they are almost certainly more intimidating than they realise, because of the reasons stated above. ${ }^{19}$ Many leaders rely on communicating and hearing from others through formal meetings, but our research shows that this is when we are at our most guarded $(56 \%$ of junior respondents say that they are somewhat or very guarded at formal meetings). Leaders need to consider carefully and continue to inquire into how they might provide different forums and situations whereby they can hear all voices. It is likely that all leaders, no matter how skilled, need to do more work than they think.

2. Question your 'little list' of whose opinion counts. Over half of senior level respondents state that they always, nearly always or usually go to the same trusted person or group when seeking ideas or opinions. This is natural-and may make sense in some cases. However, we can find ourselves in an echo chamber, listening just to those who are on our 'little list' as an interviewee of ours called it, and never hearing from those who are not. Do you find that you seek opinions from those that look predominantly like you or do you know that you hear from a wide, diverse range of voices? This is the territory of unconscious bias. Eighty-eight per cent of senior respondents say that race never or rarely affects how they listen to others. Ninety per cent insist gender does not affect how they listen. This is highly unlikely to be the case. Just because we don't want these things to get in the way, doesn't mean that they don't. Leaders must face up to their own unconscious bias-one way to do this is to really notice their response to different people as they speak up. Who do you listen to and why? Without inquiry and then awareness, even if uncomfortable, we cannot change anything.

3. Send 'speak up' rather than 'shut up' signals and responses. Do you know what you look like in meetings when others are talking? Perhaps, if you use zoom, you have caught yourself frowning or looking distracted. We send signals all the time to others, and if we are in positions of power, those signals are acutely watched by others, interpreted (accurately or not) and those others either speak up or stay silent as a result. We have come across countless leaders in our research who either don't realise the 'shut up' signals they send-or they do realise, but don't care or don't know how to change. As important is the response you have when someone does speak up. It determines whether that person, and others who are observing or who will hear about it on the grapevine, choose to speak up in the future. A raised eyebrow might seem innocuous to you, but can silence others. Leaders need to know the signals and responses they send and develop the mindfulness to change those habits in the moment. Not an easy—but not an impossible-task. ${ }^{2}$

\section{FINAL THOUGHTS}

Leaders inside and outside of healthcare are turning their attention to creating 'speak up cultures'. However, our research tells us that they can't hear what they need to hear because they underestimate, or dismiss altogether, how their power can 
silence others. They overestimate the extent to which others are speaking up as well as their own skills in listening up.

Instigating whistleblowing lines ${ }^{20}$ and training employees to be braver or insisting that they speak up out of duty, will achieve little therefore, without leaders owning their status and hierarchy, stepping out of their internal monologue and engaging with the reality of others.

Most fundamentally it requires leaders to want to listen. This is, for most, the work of a lifetime and it invites the vital question of how we should identify, recruit, train and judge our leaders.

Leaders do not and cannot possess all the answers. This can be a challenge for people who have succeeded by being expert. The future health of the healthcare system depends on it being fit for purpose for a diverse population and able to draw on an increasingly diverse set of professional disciplines. Leaders must, therefore, as an imperative, develop the capacity to encourage a broader range of voices to speak up, challenge the taken-forgranted and offer ideas. One could argue this is the imperative for leaders.

\section{Twitter Megan Reitz @MeganReitz1}

Acknowledgements The authors wish to acknowledge the assistance provided by Hult International Business School-Ashridge Executive Education, which provided support for survey data collection and analysis.

Contributors MR led the writing of this article, supported by JH. MR and JH collaborated on all aspects of the original research underlying this article.

Funding The authors have not declared a specific grant for this research from any funding agency in the public, commercial or not-for-profit sectors.

\section{Competing interests None declared.}

Patient consent for publication Not required.

Provenance and peer review Not commissioned; externally peer reviewed.

Open access This is an open access article distributed in accordance with the Creative Commons Attribution Non Commercial (CC BY-NC 4.0) license, which permits others to distribute, remix, adapt, build upon this work non-commercially, and license their derivative works on different terms, provided the original work is properly cited, appropriate credit is given, any changes made indicated, and the use is non-commercial. See: http://creativecommons.org/licenses/by-nc/4.0/.

ORCID ID
Megan Reitz http://orcid.org/0000-0003-1238-6361

\section{REFERENCES}

1 Bennis W, Goleman G, O'Toole J. Transparency: how leaders create a culture of candor. Jossey-Bass, 2008.

2 Reitz M, Higgins J. Speak up: say what needs to be said and hear what needs to be heard. London: FT Publishing, 2019.

3 Reitz M. Speaking truth to power. General Medical Council Annual Conference Keynote, London, UK, 2019.

4 Morrison EW, Milliken FJ. Organizational silence: a barrier to change and development in a Pluralistic world. Acad Manage Rev 2000;25:706-25.

5 Dyne LV, Ang S, Botero IC. Conceptualizing employee silence and employee voice as multidimensional Constructs*. J Manag Stud 2003;40:1359-92.

6 Wilkinson A, Gollan PJ, Kalfa S, et al. Voices unheard: employee voice in the new century. Int J Hum Resour 2018;29:711-24.

7 Edmondson A. Psychological safety and learning behavior in work teams. Adm Sci Q 1999;44:350-83.

8 Foucault M. Power: essential works of Foucault 1954-1984. London: Penguin, 2002.

9 Morrison EW, Rothman NB. Silence and the dynamics of power. In: Greenberg J, Edwards MS, eds. Voice and silence in organizations. Bingley, UK: Emerald, 2009: 111-33.

10 Reitz M, Nilsson V, Day E, et al. Speaking truth to power at work. Hult Ashridge research report, 2019. Available: https://tinyurl.com/y4fy4leu

11 Sherf EN, Tangirala S, Venkataramani V. Why managers do not seek voice from employees: The importance of managers' personal control and long-term orientation. Organiz Sci 2019;30:447-66.

12 Oshry B. The possibilities of organization. Boston, MA: Power and systems training, 1986.

13 Fletcher JK. Disappearing acts - gender, power and relational practice at work. Cambridge, MA: MIT Press, 1999.

14 Banaji M, Greenwald A. Blindspot: hidden biases of good people. New York: Random House, 2013.

15 Pronin E, Kugler M. Valuing thoughts, ignoring behaviour: the introspection illusion as a source of the bias blind spot. J Exp Psychol 2007;42:565-78.

16 NHS Confederation. Chairs and non-executives in the NHS: the need for diverse leadership, 2019. Available: https://www.nhsconfed.org/news/2019/06/bmeleadership-network-report

17 Fuchs B, Reitz M, Higgins J. Do you have advantage blindness? Harvard business review, 2019. Available: https://hbr.org/2018/04/do-you-have-advantage-blindness

18 Reitz M. How your power silences the truth. TEDx talk, 2018. Available: https://www. youtube.com/watch?v=Sq475Us1 KXg\&t=793s

19 Reitz M, Higgins J. Managers, you're more intimidating than you think. Harvard Business Review, 2019. Available: https://hbr.org/2019/07/managers-youre-moreintimidating-than-you-think

20 Higgins J, Reitz M. If whistleblowing is the answer, ask a better question. J R Soc Med 2019:112:453-5. 